\title{
Função paterna e estruturação de valores na adolescência ${ }^{1,2}$
}

\author{
Bárbara Lessa ${ }^{3}$ \\ Maria Cecília Queiroz ${ }^{4}$ \\ Sandra $M^{a}$ Baccara Araújo ${ }^{5}$
}

\begin{abstract}
RESUMO - O presente trabalho é resultado de uma pesquisa quantitativa sobre a "Função Paterna e Estruturação de Valores na Adolescência", realizada com 195 jovens de 14 a 20 anos, residentes no Distrito Federal, sobre a percepção deles de como o pai está ou não exercendo a Função Paterna e a influência desta sobre a formação de valores morais e sociais. Concluiu-se que para o jovem o pai funciona como o ancoradouro destes valores, tendo também a mãe uma influência forte neste processo. Percebeu-se que apesar de sentirem o pai distante e pouco participativo, sua figura foi valorizada pelo filho, mostrando a importância deste na formação da sua identidade.
\end{abstract}

Palavras-chave: adolescência, função paterna, valores morais e sociais

\section{Fatherly duties and social and moral values in adolescence}

\begin{abstract}
This current work is the result of a quantitative research about "Fatherly Duties" and "Teenager Values Estruturation", made with 195 teenagers with age between 14 and 20 years old, living in Distrito Federal, about their perception of how their father is or is not executing Fatherly Duties and the influence about this Moral and Social Values Construction. It was concluded that the teenagers feels that their father works as a safe point of this values, with their mother a strong influence on this process. It was realized that even feeling their father a little far away and not so participative, his character has been worshiped by his son, showing his value on his Identity Creation.
\end{abstract}

Key words: teenager, fatherly duties, social and moral values.

1 Pesquisa realizada com o apoio da Coordenação de Pós-Graduação e Pesquisa do UniCEUB, através do PIC/UniCEUB.

$2 \mathrm{O}$ presente artigo contou com a colaboração do aluno Daniel Marliere Letti.

3, 4, 5 Laboratório de Estudos da Família - UniCEUB.

E-mail: barbara_lessa@yahoo.com.br 
Ao se refletir sobre Função Paterna, uma das principais questões que se coloca é a de tentar definir especificamente a que esta se refere. As constantes transformações ocorridas no contexto familiar, como o aumento de divórcio, recasamentos, famílias mononucleares, trazem à tona uma discussão sobre a atuação do pai e sobre sua real relevância na educação dos filhos.

Segundo Rappaport (1981),

"A constatação da importância do pai para o desenvolvimento da criança partiu das colocações da psicanálise relativas às vivências edípicas. Assim, o pai começaria a ter importância no desenvolvimento da criança a partir dos três anos aproximadamente, e sua atuação se diferencia no caso da menina e do menino. Em ambos os casos, o pai seria fundamental no processo de formação do Superego, no que se refere à interiorização de uma série de regras morais que são fundamentais para o convívio social” (p. 95).

Ainda sobre esse assunto, Hurstel (1999) destaca que

“o pai é, no complexo de Édipo, aquele ao qual a mãe se refere para a criança, aquele que vem ocupar a terceira posição. Todos esses pais participam da função fálica que os nomeia e lhes dá o lugar que ocupam. Em todos esses casos, o pai é o 'sustentador da lei', ele está na posição de representá-la para o sujeito: ele não é a lei, não a faz, ele é o seu representante” (p. 78).

Reafirmando o que foi acima citado, mas com uma perspectiva mais ampla centrada na sociedade como um todo e não só na microestrutura social (família), Araújo (2001) afirma que a figura paterna designa o princípio de autoridade que sustenta "o fio e a trama" do tecido social e que esse princípio garante o funcionamento das instituições ou de quaisquer formações coletivas. Assim, uma sociedade resultaria da aceitação comum de códigos, de normas ou leis - impostas e/ou introjetadas - capazes de assegurar minimamente a permanência do vínculo ou laço social (p. 17).

Destacando a importância dos pais no processo de desenvolvimento da identidade do adolescente, Levisky (1997) diz que "os pais são modelos identificatórios para os filhos, e os líderes de uma nação podem ser incorporados como modelos do caráter nacional, principalmente pela juventude” (p. 25).

Outeiral (2003) levanta a questão da perda da proximidade da criança/ adolescente com os vários modelos identificatórios, sendo estes de extrema importância para o adolescente que está em busca de sua identidade. Segundo ele, essa perda ocorreu com a passagem da família patriarcal para a família nuclear 
na qual, geralmente, ambos os pais estão inseridos no mercado de trabalho (p. 16).

Noto (2001) aponta como uma das tarefas básicas da função paterna

"ser o provedor, aquele que traz os recursos do mundo externo, proporcionando as condições necessárias para que a mãe possa permanecer disponível para cuidar do filho. Cabe ao pai ser o suporte da mãe, tanto econômico como emocional, proporcionando-lhe então a tranqüilidade necessária para que ela possa desempenhar o seu papel" (p. 317).

Com o declínio da família patriarcal, a entrada da mulher no mercado de trabalho, a "luta" ombro a ombro de homens e mulheres por status, poder e recursos financeiros, o homem se viu "sem papel" na família pós-moderna. Para Araújo (2001) "no interior da família, das organizações e das instituições, cada vez mais as mulheres ocupam o lugar de ordenadoras da vida grupal, são elas que dão a "lei'" (p. 24). O cuidado com os filhos deixou de ser exclusivamente da mulher e a manutenção do orçamento familiar exclusivamente do homem. Esse fato traz ao homem (pai) a possibilidade de maior participação na educação e na saúde dos filhos, surgindo entre pais e filhos um elo afetivo maior. Nesse sentido o homem passa a desempenhar tarefas antes impensáveis para ele.

Dessa perspectiva, o que se observa atualmente está longe de ser uma completa troca de papéis entre homens e mulheres, entre pai e mãe, mas o esmaecimento da fronteira que separa os papéis de cada um.

Levisky (1997) citando Giannetti enfatiza que

"o enfraquecimento da família intacta vem tendo efeitos negativos sobre os seus elos mais fracos. Mais do que a escola, a família é a principal responsável pela transmissão social de um sentido de valores que induz os mais jovens a desenvolver suas capacidades morais e cognitivas (...) nada substitui a presença dos pais que cooperem ativamente na criação dos filhos e valorizem o empenho escolar (...) A família é a primeira, a menor e a mais importante escola" (p. 25).

Questiona-se, a partir destes levantamentos, como os adolescentes estão estruturando sua identidade diante dessas mudanças ocorridas no contexto familiar e, por conseguinte, no contato com os pais, lembrando que são os valores, a lei, os limites oferecidos se não pelos pais, pela sociedade, formadores de um continente, um espaço seguro que possibilita a construção de uma identidade saudável no adolescente. 


\section{Problema e hipótese}

O trabalho se justificou por possibilitar a abertura de novas perspectivas sobre o processo de estabelecimento da Função Paterna na estruturação de normas e valores na adolescência, levando-se em consideração a dificuldade atual desta estruturação, que se reflete no aumento da violência, do suicídio, dos casos de depressão nos jovens, dentre outros. Os resultados, análises e conclusões obtidas por meio deste, poderão auxiliar na compreensão deste processo e, concomitantemente, favorecer a constituição desta estruturação como um alicerce para a construção de uma identidade saudável no adolescente.

A presente pesquisa teve como objetivo verificar a percepção que os adolescentes têm do exercício da Função Paterna pelo pai na estruturação de valores de seus filhos adolescentes, dentro do contexto da atualidade do Distrito Federal.

A hipótese levantada refere-se a se o adolescente percebe o pai no exercício da Função Paterna como sendo um ancoradouro de valores morais e éticos.

\section{Metodologia}

Formulou-se um questionário com 16 questões relacionadas à atuação do pai. Este questionário foi reproduzido e fez-se uma aplicação piloto na qual foi pedido que os adolescentes o respondessem sem o auxílio do aplicador e informassem sobre possíveis dificuldades de respondê-lo.

Reformulou-se algumas questões do questionário, obtendo-se assim, o instrumento final utilizado na pesquisa.

Aplicou-se este questionário, registrado pelas pesquisadoras, em escolas públicas e particulares e shoppings da cidade, em 195 adolescentes, com idades entre 14 e 20 anos, de ambos os sexos, moradores do Distrito Federal e de escolaridade diversa.

Os resultados foram analisados de acordo com a metodologia da análise quantitativa.

\section{Resultados e Discussão}

A população pesquisada foi predominantemente constituída por adolescentes de $15(20,52 \%) 16(20,51 \%)$ e 17 anos $(18,46 \%)$, obtendo-se assim um total de $59,49 \%$ de adolescentes entre essas idades. A amostra foi em sua maioria feminina $(65,13 \%)$ 
Quanto ao local de moradia desta, observou-se que 56,42\% são moradores do Plano Piloto, restando, assim, 43,58\% moradores das Cidades Satélites.

Com relação às idades dos pais da amostra pesquisada, notou-se a prevalência de idades entre 40 e 49 anos (54,86\%). Com relação a esses dados, pode-se dizer que esses pais são relativamente jovens levando-se em consideração a idade da população pesquisada.

Pôde-se observar que $67,69 \%$ da amostra foi formada por estudantes do ensino médio. Este dado é coerente levando-se em consideração a idade dos adolescentes entrevistados e, mais especificamente, a porcentagem da amostra, composta em sua maioria por adolescentes entre 15 e 17 anos $(59,49 \%)$, como já foi dito anteriormente.

Quanto às pessoas com quem os adolescentes moram, a pesquisa aponta que $63,58 \%$ deles moram com o pai e a mãe. Este dado remete a indagação se, ao contrário do que se pensa atualmente, o número de famílias constituídas por pai, mãe e filho(s), supera o número de famílias com pais divorciados ou solteiros. Para esse dado obtido, levantou-se o questionamento sobre a transição estrutural das famílias. O número de famílias divorciadas realmente supera o número de famílias que se mantém casadas, ou estamos diante de uma volta ao casamento estável?

Mostrou-se que cerca da metade dos adolescentes $(52,31 \%)$ considera o pai participativo. A outra metade da amostra (47,59\%) o considera pouco participativo ou ausente. Contudo pôde-se observar que a maioria deles $(64,62 \%)$ sente o contato que tem com o pai superficial ou mediano, restando 35,36\% de adolescentes que o vê como profundo. A suposta incoerência observada nos dados pode ser discutida se pensarmos no momento evolutivo vivenciado pela amostra.

Chamou-nos ainda a atenção o fato de que a maioria dos adolescentes $(68,21 \%)$ julga o contato com o pai, apesar de superficial e mediano, como sendo bom ou ótimo. A minoria desta amostra $(5,64 \%)$ o considera péssimo.

Pôde-se observar também que a grande maioria dos adolescentes $(85,64 \%)$ se considera membro de suas famílias. Notou-se, com esse dado, que os adolescentes se consideram inseridos nelas.

Verificou-se que 59,48\% dos adolescentes respondeu "não" ou "às vezes" quando questionados sobre a liberdade que tinham para conversar com seus pais. Comparando este resultado com os resultados apresentados sobre como consideram o pai e o contato com este, pôde-se supor a ocorrência de um distanciamento entre pais e filhos, distanciamento este considerado natural, tendo em vista que para ser tornar autônomo e independente o jovem necessita de outras figuras de identificação. 
Quanto à conversa entre os adolescentes e os pais, encontrou-se que a grande maioria dos pesquisados $(66,66 \%)$ mantém um diálogo com estes, no qual ambos falam e são escutados, embora $57,95 \%$ tenham afirmado que possuem um pai que ou não tem ou somente às vezes tem tempo para eles.

Questionou-se de que tempo e de que diálogo falavam os adolescentes, na medida em que cerca da metade deles $(47,18 \%)$ respondeu ser suficiente o tempo que o pai lhe dedica, enquanto a outra metade $(52,82 \%)$ respondeu que o tempo é suficiente somente às vezes ou que não é suficiente. Será esta resposta uma reclamação do adolescente?

Mais da metade dos adolescentes $(68,72 \%)$ afirma que os valores e conhecimentos que seus pais lhes transmitiu estão sendo úteis a sua vida, embora somente pouco mais da metade deles $(54,36 \%)$ aplica estes valores em suas vidas.

Notou-se que os valores menos apontados pelos adolescentes, no que se refere aos valores transmitidos pelos pais, foram competitividade $(49,23 \%)$, respeito ao meio ambiente $(50,25 \%)$, ética $(68,71 \%)$ e cidadania $(69,74 \%)$. Os mais apontado foram honestidade $(87,17 \%)$, responsabilidade $(84,11 \%)$ e dignidade $(84,1 \%)$.

Verificou-se, que dentre os valores não transmitidos pelos pais, os que os adolescentes mais gostariam que tivessem sido seriam: o respeito ao meio ambiente $(25,64 \%)$, a competitividade $(22,05 \%)$, a ética $(19,48 \%)$ e a cidadania $(18,46 \%)$. Vale ressaltar que a competitividade, mesmo sendo apontada como o valor menos transmitido pelos pais, como foi dito anteriormente, não foi o valor mais citado por eles como o que eles gostariam que tivesse sido transmitido. Este fato pode ter ocorrido pela palavra competitividade sugerir ao jovem o significado de rivalidade, de luta e não como uma qualidade necessária para os dias atuais.

Notou-se que $76,41 \%$ dos adolescentes pesquisados busca na mãe os valores que não foram transmitidos pelo pai, indicando assim, a importância da mãe também como sustentadora dos valores e normas sociais para os adolescentes. Mais da metade deles também indicou os amigos $(66,67 \%)$ e a escola $(57,43 \%)$ como referenciais nos quais os valores são buscados por eles. Para Outeiral (2003) além da identificação dos adolescentes, principalmente com os pais, o grupo de amigos, os astros de cinema, televisão e música e os professores escolares constituem importantes elementos na construção da sua identidade.

A pesquisa mostrou que $62,05 \%$ dos adolescentes disse admirar o pai, 29,23\% afirmou admirá-lo em termos e uma minoria, 8,72\%, não admirar.

Apesar disto, somente $36,92 \%$ dos adolescentes entrevistados manifestou a intenção de educar seus filhos da mesma maneira que seu pai lhe educou, sendo que $63,08 \%$ deles disse que não educaria da mesma forma ou educaria em termos. 
Observou-se que os valores menos apontados pelos adolescentes, no que se refere aos recebidos dos pais que eles passariam para seus filhos, foram competitividade $(46,22 \%)$, respeito ao meio ambiente $(52,3 \%)$, ética $(69,23 \%)$ e cidadania $(70,76 \%)$, sendo estes os mesmos valores que os adolescentes apontaram como menos transmitidos a eles.

De maneira geral, levando-se em consideração o caráter probabilístico da pesquisa, pode-se dizer que os resultados apresentaram evidências de um distanciamento entre pais e filhos, mas que, apesar disto, os adolescentes estão relativamente satisfeitos com esta relação. A contribuição efetiva da mãe na estruturação de valores no adolescente, pode estar influenciando no fato deles não estarem insatisfeitos com a relação que mantêm com o pai.

Vale ressaltar a carência de valores como ética e cidadania que os adolescentes estão sofrendo, sendo estes valores essenciais para uma constituição saudável da identidade e para a manutenção do laço social do indivíduo com a sociedade. A competitividade também pode estar sendo negligenciada, considerando ser de extrema importância para os dias atuais.

\section{Conclusão}

A hipótese levantada referiu-se à percepção do adolescente do pai no exercício da Função Paterna como sendo um ancoradouro de valores morais e éticos. Pôdese concluir, a partir da pesquisa realizada e da análise de seus resultados, que há evidências de que a Função Paterna está sendo exercida em parte pelos pais (homens), pelo menos no que se refere à estruturação de normas e valores sociais para o adolescente, no sentido de que esses pais, apesar de não terem tempo suficiente para os filhos e manterem um contado superficial ou mediano com eles, têm transmitido valores e conhecimentos úteis para vida dos adolescentes. A pesquisa também apresentou indícios de uma forte atuação da mãe neste processo, podendo ser caracterizada como uma fonte, um referencial no qual os adolescentes têm a oportunidade de buscar valores para as suas vidas.

A pesquisa indicou um distanciamento vigente entre os adolescentes e o pai e que estes adolescentes, apesar de admirá-los, não demonstram uma vontade de perpetuar a forma como a educação lhes foi oferecida. Este fato pode estar ligado à necessidade dos adolescentes de se desvencilharem daqueles que assumiram forte influência na sua formação pessoal na infância, demonstrando, assim, um processo de estruturação de sua individualidade. 


\section{Referências}

ARAUJO, J.N.G., SOUKI, L. G. \& FARIA, C. A. P. (2001). Figura Paterna e ordem social. Belo Horizonte: Autentica.

HURSTEL, F. (1999). As novas fronteiras da paternidade. (Trad. Emma Elisa Carneiro de Castro). Campinas, SP: Papirus.

NOTO, I.S. (2001). Mater certa, Pater incertus: sobre a possibilidade de exercer a função paterna. Revista Brasileira de Psicanálise, São Paulo. vol. 35, 317-333.

OUTEIRAL, J. O. (2003)._Adolescer - Estudos sobre adolescência. Rio de Janeiro: RevinteR.

RAPPAPORT, C. R., FIORI, W.R. \& DAVIS, C. (1981/1982). Psicologia do Desenvolvimento - A idade escolar e a adolescência. São Paulo: EPU.

LEVISKY, D.L. (1997). Adolescência e violência - Conseqüências da realidade brasileira. Porto Alegre: Artes Médicas. 